\title{
DENTAL AWARENESS AND ORAL HEALTH OF PREGNANT WOMEN IN POLAND
}

\section{EWELINA GASZYŃSKA ${ }^{1}$, JUSTYNA KLEPACZ-SZEWCZYK ${ }^{2}$, ELŻBIETA TRAFALSKA ${ }^{1}$, ANNA GARUS-PAKOWSKA ${ }^{1}$, and FRANCISZEK SZATKO ${ }^{1}$}

\author{
${ }^{1}$ Medical University of Lodz, Łódź, Poland \\ Department of Hygiene and Epidemiology \\ ${ }^{2}$ Medical University of Lodz, Łódź, Poland \\ Department of Endodontics
}

\begin{abstract}
Objectives: The level of dental awareness of a pregnant woman affects the sanitary condition of her own teeth and the health of the child to be born. Poor oral health is considered to be a probable risk factor for the pre-term birth or low birth weight. The aim of this work was to assess the level of oral health knowledge that determines oral health condition of pregnant women in Poland. Material and Methods: Empirical data were obtained from the National Monitoring of Oral Health and Its Determinants, financed by the Ministry of Health. This socio-epidemiological study assessed oral health status and dental health awareness, which affects that status. Study subjects included 1380 pregnant women at the age ranging from 15 to 44, randomly-selected from urban and rural environments. Dental health status was recorded in the clinical examination sheets supplied by the World Health Organization, and the socio-medical data were recorded in the questionnaire interview sheets. Results: Almost 3/4 of the pregnant women evaluated their dental health as unsatisfactory or poor. Over $60 \%$ of the pregnant women rated their knowledge and practical skills concerning care of their own teeth and of the child to be born as limited, inadequate or none. Only $40 \%$ of the pregnant women provided right answers to the questions about dental issues. Conclusions: Low oral health awareness results in poor oral health status of the study subjects. A statistical pregnant woman has a total of 13 teeth showing the symptoms of tooth decay or caries. Over $70 \%$ of the pregnant women developed gingivitis or periodontitis. There is an urgent need in Poland to make the European principle of treating pregnant women as a dentally vulnerable group obligatory.
\end{abstract}

Key words:

Oral health, Pregnant woman, Dental health surveys, Dental care, Self evaluation

\section{INTRODUCTION}

Pregnancy is a challenging physiological and emotional experience for a woman. The majority of pregnant women, for the sake of good health of the child to be born as well as because of material benefits guaranteed for pregnant women by welfare system, scrupulously attend scheduled medical examinations. The percentage of pregnant women under the care of a gynecologist exceeds $99 \%$, and more than $82 \%$ of them report visiting the doctor within the first 12 weeks of pregnancy [1]. However, this high rate of visits to gynecologists does little to improve awareness of the negative effects of poor oral health of a mother on the fetus and neonate.

About 300 species and sub-species of microorganisms colonizing oral cavity, as a result of hormonal changes, immune imbalances and changing cellular metabolism,

Received: January 7, 2014. Accepted: November 20, 2014.

Corresponding author: E. Gaszyńska, Medical University of Lodz, Department of Hygiene and Epidemiology, Jaracza 63, 90-251 Łódź, Poland (e-mail: ewelina.gaszynska@umed.lodz.pl). 
may cause infections of the essential organs, such as the heart or kidneys [2,3]. During pregnancy, permeability of blood vessels increases, causing swelling of the gingival [4]. Reduction in epithelial keratinization weakens the protective role of epithelium. If this change is accompanied by a lack of concern for oral hygiene, plaque and multiplying microorganisms may cause gingivitis and periodontitis. Periodontal diseases are listed as one of the causes of pre-term birth or low birth weight $[2,5,6]$.

Growth of pathogenic oral flora is enhanced by unhealthy dietary habits: increased intake of simple sugars as well as higher frequency of intake of snacks between the main meals.

Very early and rapid development of dental caries in the deciduous teeth of children exposed to the pathogens transmitted from the mother's oral cavity constitutes an important reason that justifies the need for research on health awareness and promotion of healthy behaviors among pregnant women. Reducing bacteria, especially the cariogenic Streptococcus mutans subspecies, is one of the goals of early caries prevention strategies targeted both at pregnant women and mothers raising pre-school children $[5,7,8]$. Very poor dental health in pre-school children is particularly worth noting here. A Polish statistical child at the age of 6 has over 5 teeth affected by caries and only 1 in 10 of those teeth is filled [9]. This alarming epidemiological picture raises the question to what extent does dental awareness of pregnant women and mothers raising pre-school children contributes to this situation?

\section{Aim of the study}

To assess the level of dental health awareness of pregnant women and their oral health status. The practical aim is to motivate decision-makers at the nationwide and provincial level to consider pregnant women as a dentally vulnerable group.

\section{MATERIAL AND METHODS}

Empirical data were obtained from the National Monitoring of Oral Health and Its Determinants study funded by the Ministry of Health. As part of this project, consecutive subpopulations at the age of $6,12,18,35-44,65-74$ years or other major groups, such as children with disabilities or, as in the present case, pregnant women are included into the study [10].

The study group was specified in stratified sampling. In the 1st stage 7 voivodships were drowned from a group of 16. In the 2nd stage from each of the 7 voivodships 2 hospitals with obstetric and gynecological wards were drowned (total number - 14 hospitals). Each time during selection of these 2 hospitals their localization was considered; 1 located in mainly rural/small town region and other in the urban region were selected. Each of 7 dental teams had to examine 200 consecutive pregnant women who were admitted to the hospital due to the childbirth after the date of the 1st November.

The time of the study was determined by the different number of hospitalizations of women being in the 3rd trimester of pregnancy. In the wards with a high number of hospitalizations data were recorded during the period of 2 weeks, and in the wards with a low number of hospitalizations the study was performed for a period longer than 1 month. Attitude to the study of the women hospitalized due to delivery (in the $3 \mathrm{rd}$ trimester) was very positive. It might be so due to the fact that in the last part of the study they were informed about methods of dental caries prophylaxis as well as methods of dental care in the case of their children and their own oral health status, and treatment needs. Participation in the study was voluntary. The response rate was high and reached $98 \%$. As a result, data from 1380 pregnant women were obtained. The age of the respondents ranged from 15 to 44 years (Table 1). Clinical assessment of oral health status was supervised by prof. Maria Wierzbicka from the Medical University of Warsaw. Oral health status of the pregnant women was 
Table 1. Characteristics of the analyzed population of pregnant women by environment (urban/rural) and age

\begin{tabular}{lcccc}
\hline \multirow{2}{*}{ Setting } & \multicolumn{4}{c}{$\begin{array}{c}\text { Respondents } \\
(\mathrm{N}=1380) \\
{[\mathrm{n} \%]}\end{array}$} \\
\cline { 2 - 5 } & $15-24$ years old & $25-29$ years old & $30-44$ years old & total \\
\hline Urban & $186(13.5)$ & $314(22.8)$ & $234(16.9)$ & $734(53.2)$ \\
Rural & $255(18.4)$ & $206(14.9)$ & $185(13.5)$ & $646(46.8)$ \\
Total & $441(31.9)$ & $520(37.7)$ & $419(30.4)$ & $1380(100)$ \\
\hline
\end{tabular}

evaluated in a clinical examination and the data were recorded using unified charts recommended by the World Health Organization (WHO). Dental assessment was carried out using a dental mirror, probe and optic fiber head lamp.

Reliability of the study in each hospital was controlled by a regional dental consultant from the dental department of the local medical university or dental clinic. According to WHO recommendations, 2 dental indexes were calculated: decayed, missing and filled teeth (DMFT) (total number of decayed, missed and filled teeth), and community periodontal index (CPI) [11].

The data on dental health awareness and its determinants: social, economic, organizational and cultural factors were collected in the questionnaire interview designed in the Medical University of Lodz by prof. Franciszek Szatko. The study protocol was approved by the Medical University of Warsaw Bioethical Committee.

Analysis of dental awareness and oral health among the pregnant women $(\mathrm{N}=1380)$ was performed taking into account the 2 settings of residence: urban and rural. The questionnaire designed for the study provided also other data, i.e., on economic status of the participant's family, education of the participant, number of children in the family. As initial statistical analysis did not reveal any significant associations between dental awareness and the above mentioned factors, these data were not included in the presented analysis. Thus, the authors concentrated on dental awareness and its association with oral health status.
Statistical analysis was performed using the Pearson's correlation and $\mathrm{Chi}^{2}$ test, with the Statistica PL software. P-values less than $0.05(\mathrm{p}<0.05)$ were considered as statistically significant. In order to determine the compatibility of subjective and objective evaluations of oral health the kappa Cohen's coefficient $(x)$ was implemented.

\section{RESULTS}

\section{Dental health of pregnant women}

Before the clinical examination the participants were asked to assess their oral health status using a 5-point Likert scale (1 - very good; 5 - very poor) (Table 2 ). One in 4 women assessed their oral health status as very good or good. Oral health status was evaluated/rated as "satisfactory" by $59.6 \%$ of the respondents. Only 14,7\% of the respondents perceived their oral health negatively. The pregnant women living in urban areas significantly more often than the rural inhabitants, had a positive (very good or good) opinion on the state of their dentition (31.5\% and $19.2 \%$, respectively, $\mathrm{p}<0.001$ ). Compatibility of the subjective and objective evaluations of oral health was very low/slight $(x=0.0754)$. Majority of the pregnant women formed an overly optimistic judgment of their oral health status.

According to the clinical dental examination, only $0.4 \%$ of the pregnant women were free of dental caries, and the mean value of the DMFT index was 12.9. There were no statistically significant differences between DMFT due to the rural or urban setting. Only $15.2 \%$ of the women did not need any dental treatment. More than $38 \%$ of the 
Table 2. Subjective (self-assessed) and objective (clinical examination) assessments of the oral health status of the pregnant women from urban and rural settings

\begin{tabular}{lccccc}
\hline \multirow{2}{*}{$\begin{array}{c}\text { Self-assessed oral } \\
\text { health status }\end{array}$} & \multicolumn{2}{c}{ Clinical examination (objective) } & \multicolumn{2}{c}{$\begin{array}{c}\text { Setting } \\
{[\mathrm{n}(\%)]}\end{array}$} & \multirow{2}{*}{ Total } \\
\cline { 2 - 5 } & clinically poor & clinically good & urban & rural & \\
\hline Very good / good & $225(32.7)^{*}$ & $130(18.7)$ & $231(31.5)^{*}$ & $124(19.2)$ & $355(25.7)$ \\
Satisfactory & $335(48.8)^{*}$ & $487(70.3)$ & $405(55.2)^{*}$ & $417(84.6)$ & $822(59.6)$ \\
Poor / very poor & $127(18.5)$ & $76(11.0)$ & $98(13.3)$ & $105(16.2)$ & $203(14.7)$ \\
Total & $687(100)$ & $693(100)$ & $734(100)$ & $646(100)$ & $1380(100)$ \\
\hline
\end{tabular}

* Significant difference between poor and good objective oral health status or urban and rural inhabitants: $\mathrm{p}<0.001$.

individuals taking part in the study had 2 to 3 teeth requiring dental treatment. Gingivitis and periodontitis were found in $64 \%$ and $12 \%$ of the women, respectively. However, pregnant women are predisposed to gingivitis due to hormonal changes, and in $42.3 \%$ of the pregnant women removal of heavy dental calculus deposits was needed.

According to the outcomes of clinical examination, the study population was divided dichotomously into the subgroups with "good" and "poor" oral health status. The subgroup with poor oral health status included the women who had more than 12 teeth affected by caries (DMFT > 12), or had at least 1 tooth removed due to caries (missing tooth MT $>1$ ) or diagnosed with heavy periodontal problems (CPI > 2). The fact that a great majority of the pregnant women with objectively poor oral health (about 70\%) was not aware of that (Table 2) is worth noting. Nearly the same percentage of the urban and rural inhabitants had realistic opinions on their dentition.

\section{Dental awareness of pregnant women}

Sixty one percent of the respondents rated their knowledge and practical skills concerning care for their teeth and the child's to be born as limited, inadequate or none. Only 39\% identified their dental awareness as "very good" or "sufficient". There were no statistically significant differences in self assessed dental awareness between the pregnant women from the urban and rural settings
(Table 3). A positive correlation was found between the self-assessed sufficient knowledge of the pregnant women and their oral health $(r=0.67)$. The respondents with a "better" oral health often assessed their dental awareness as sufficient or very good, and the women with the "poorer" state of oral health more often considered their knowledge to be limited or insufficient.

However, $78.1 \%$ of the respondents agreed with the statement that healthy teeth and gums during pregnancy are essential for the overall health of the child to be born. Nevertheless, only 1 in 2 women (53\%) visited a dentist during pregnancy. Three percent of them were referred to a dentist by the gynecologist.

There were no statistically significant differences between the women from the urban and rural areas (Table 3).

In the next part of the study, the participants were asked to mark each of 10 statements as true or false, or select the 3rd option: "I don't know". The statements dealt with the well-known problems, such as the cariostatic effect of fluoride, and some difficult issues, such as: inheritance of caries and caries dynamics (Table 4).

The frequency of correct answers varied from $10 \%$ to $76 \%$, median $39.5 \%$. A relatively high percentage of the responses: "I do not know" (median: $31.2 \%$ ) revealed that 1 in 3 of the study subjects was ignorant of many dental problems. Almost $1 / 2$ of the mothers did not know about the different content of fluoride in commercially available brands 
Table 3. Self-assessed level of dental knowledge and practical skills concerning dental care among the subjects from urban and rural settings

\begin{tabular}{|c|c|c|c|}
\hline \multirow[t]{2}{*}{ Parameter } & \multicolumn{3}{|c|}{$\begin{array}{c}\text { Respondents } \\
(\mathrm{N}=1380) \\
{[\mathrm{n}(\%)]}\end{array}$} \\
\hline & urban & rural & total \\
\hline \multicolumn{4}{|l|}{ Self-assessed dental knowledge } \\
\hline insufficient or none & $31(4.2)$ & $51(7.9)$ & $82(5.9)$ \\
\hline limited & $392(53.4)$ & $364(56.3)$ & $756(54.8)$ \\
\hline sufficient or very good & $311(42.4)$ & $231(35.8)$ & $542(39.3)$ \\
\hline \multicolumn{4}{|c|}{$\begin{array}{l}\text { Relationship strength between pregnant women oral health and fetus } \\
\text { health }\end{array}$} \\
\hline weak & $23(3.1)$ & $46(7.1)$ & $69(5.0)$ \\
\hline to some moderate extent & $127(17.3)$ & $106(16.4)$ & $233(16.9)$ \\
\hline strong & $584(79.6)$ & $494(76.5)$ & $1078(78.1)$ \\
\hline
\end{tabular}

Table 4. Pregnant women's evaluation of the statements dealing with oral health

\begin{tabular}{|c|c|c|c|}
\hline \multirow[t]{2}{*}{ Statement } & \multicolumn{3}{|c|}{$\begin{array}{c}\text { Respondents } \\
(\mathrm{N}=1380) \\
{[\%]}\end{array}$} \\
\hline & correct answer & incorrect answer & lack of knowledge \\
\hline $\begin{array}{l}\text { Caries develops rapidly in children and youths, while in adults its } \\
\text { development is much slower }\end{array}$ & 39.1 & 33.0 & 27.9 \\
\hline $\begin{array}{l}\text { If parents had a high tendency to develop caries, their children will, for } \\
\text { hereditary reasons, have their teeth strongly affected by caries (false) }\end{array}$ & 34.5 & 28.0 & 37.5 \\
\hline $\begin{array}{l}\text { In a family with a high tendency to develop caries, when } \\
\text { the 1st deciduous tooth appears in the child, it is advisable to use } \\
\text { toothpaste with high fluoride content (like that used by adults) } \\
\text { to prevent caries (false) }\end{array}$ & $55.1^{*}$ & 10.5 & 34.4 \\
\hline Fluoridation of drinking water reduces the incidence of caries & $25.7^{*}$ & 12.8 & 61.5 \\
\hline Vitamin D augments normal development of bones and teeth & $66.5^{*}$ & 4.6 & 28.9 \\
\hline $\begin{array}{l}\text { It is not necessary to pay much attention to the treatment of the } \\
\text { deciduous teeth - both the treated and the untreated ones will soon } \\
\text { drop out (false) }\end{array}$ & $10.4^{*}$ & 76.5 & 13.1 \\
\hline $\begin{array}{l}\text { Children with many deciduous teeth extracted because of caries often } \\
\text { develop occlusion defects }\end{array}$ & $31.1^{*}$ & 12.3 & 56.6 \\
\hline $\begin{array}{l}\text { Eating an apple before going to sleep is an effective substitute for } \\
\text { washing the teeth by a child in the evening (false) }\end{array}$ & 7.5 & 75.6 & 16.9 \\
\hline $\begin{array}{l}\text { The main function of dental floss is to remove food debris rather } \\
\text { than to eliminate plaque (false) }\end{array}$ & $73.7^{*}$ & 9.9 & 16.4 \\
\hline Gum disease is manifested, e.g., by gum bleeding & $76.3^{*}$ & 6.6 & 17.1 \\
\hline
\end{tabular}

* Significant difference between the chosen answers: $\mathrm{p}<0.05$. 
of toothpaste, and were ignorant of the rules for their different use by preschool children, adolescents and adults. About $15 \%$ of the respondents were convinced about major genetic determination of dental caries.

The present study has provided yet another very disturbing information. One in 5 of the future mothers was skeptical about treatment of deciduous teeth in the child to be born. At the same time, nearly $70 \%$ of the mothers were not aware of more frequent occurrence of orthodontic defects in school children in whom a significant number of deciduous teeth were removed due to caries.

However, nearly all the pregnant women were familiar with the term dental floss, but $1 / 4$ of them claimed that its main purpose is to remove food debris after meals rather than to remove plaque from the teeth, or did not know the purpose of its use at all.

The majority of future mothers did not have problems linking bleeding gums with a gum disease.

There were no statistically significant differences between dental health awareness of the studied groups in the rural and urban settings.

\section{Sources of dental knowledge}

As the main source of their dental knowledge, the respondents most frequently mentioned information from a family doctor or a dentist/dental hygienist (58\%), and from magazines or guidebooks for pregnant women and parents (57\%). Other sources of information (almost 30\%) included: television, radio and the Internet, that are not fully reliable ones and may even discourage a mother from the daily oral care (e.g., vaccine against dental caries, a 3rd set of teeth, pain-free treatment gel).

\section{DISCUSSION}

The false belief in a high hereditary susceptibility to caries, noted also by authors studying other subpopulations of Poland [8,9] is particularly confusing. It may result in restrain from prophylaxis and negating introduction of positive dental behaviors (cleaning the teeth at least twice a day, the use of formulations containing fluoride, visiting a dentist at least twice a year).

Dental status and dental awareness might be indirectly associated with the place of residence of the respondents. This relationship might be attributed to a higher education level, better socio-economic status and greater availability of dental care in the case of the residents of urban areas compared to those from the rural ones. In the study we found only few differences between dental awareness of the women from different settings. Their dental awareness resulted from individual engagement and bring-up process, because there is lack of dental programs in Poland addressed to pregnant women.

The results of subsequent monitoring studies revealed very low knowledge about the necessity of conservative treatment of deciduous teeth in 3-year-olds $(0.02 \%)$ and in 6-year-old children (only 10\%) [12].

Pregnant women in the developed European countries are classified as dentally vulnerable groups. Therefore, a gynecologist is obliged to refer a pregnant woman with oral problems to the dentist. The statutory obligations of a dentist include not only full oral sanitation of the pregnant patients, but also thorough theoretical and practical education on preventive dentistry during pregnancy and childbirth. Involvement of medium-level dental professionals in oral health education of pregnant women is also obligatory. The benefits of inclusion of pregnant women into the dentally vulnerable group include: free of charge restorative and preventive services, and priority of the admission when immediate admission is not accessible to all the patients. More than $1 / 2$ of the pregnant women visited a dentist during pregnancy, but this visit was not a result of an invitation from the system of dental or gynecological care, but it was solely the pregnant women's own initiative.

As shown above, low dental awareness in about $40 \%$ of the pregnant women has its origin in the lack of educational programs in the Polish education system from kindergarten 
to the secondary school $[9,10,12]$. Moreover, $58 \%$ of the pregnant women who indicated a dentist as the main source of dental knowledge, also noticed the passivity of the dentists who educate the patients only if asked.

The number of studies on dental awareness of pregnant women in Poland is limited [7]. However, the corresponding data on mothers raising preschool children are easily accessible [9,12]. Similar mechanisms of consciousness affect both Polish pregnant women and mothers of children at preschool age. By extrapolating the results of one subpopulation to the other, it seems reasonable to conclude about similar trends for improved dental awareness of pregnant women. In the last decade some positive trends in mothers' dental behavior were observed, $20 \%$ more mothers limited sweets eaten by their children and encouraged them to clean the teeth twice a day [12]. In the year 2000 , over $50 \%$ of the mothers bringing up 6-year-old children claimed that there was no use to care about primary dentition being unaware of the strong relationship between untreated caries in deciduous teeth and caries in permanent dentition [10]. In the 2010 study, "only" 26\% of the mothers expressed a similar view.

Other researchers dealing with the issues of dental care for pregnant women clearly point to the low level of awareness in this group. Chłapowska and Opydo-Szymaczek [13], Janas et al. [14], Szyszkowska and Chmielewska [15], and Wochna-Sobańska [4] have indicated the need for implementation of education activities (programs) targeted at pregnant women and new mothers.

Other authors, mainly from the countries or regions that, similarly to Poland, do not have dental education programs for pregnant women, have also revealed very low dental awareness in that group [6,16-18]. According to those authors, a specific advantage should be taken of the pregnancy for the development of health consciousness and healthy behaviors in women.

Cruz et al. [19] and Clifford et al. [20] in their programs for pregnant and new mothers have made use of a number of teaching aids, leaflets, bags, magnets, bibs for babies and educational DVDs with instructions. These activities have been very positively received by the women and had a measurable impact on improving their health awareness and behavior.

Conclusions of almost all those authors have formed a general message that pregnant women should be classified as a dentally vulnerable group in the countries that do not respect the rule yet, and that the range of prevention activities in the countries that already comply with this rule should be expanded [6,19,21,22].

Current self-assessment is the primary motivator for pregnant women to undertake or refrain from taking numerous important steps, such as urgent visit to a dentist, starting the thorough cleaning of the teeth, use of dental floss or rinsing oral cavity with a rinsing liquid, or including products containing fluoride into the diet, etc.

Several limitations of our study should be addressed. First, because of the cross-sectional design, it was not possible to assess the dynamics of changes in dental awareness of the pregnant women. As far as we know, in the last 3 decades there were no other big studies on dental awareness of pregnant women in Poland. Second, because of the fact that we focused mainly on negative consequences of insufficient dental awareness, oral health status was described briefly. Third, initial analysis revealed no relationship between many socio-economic factors that were not mentioned in the study. We think that this low level of dental awareness in different socio-economic groups might result from the lack of dental programs addressed to people at different age.

\section{CONCLUSIONS}

Despite the above limitations, as the study population is representative for Polish population we conclude that:

- About $40 \%$ of pregnant women do not have the basic dental knowledge needed both during pregnancy as well as for education of children at the early stages of their development. 
- Poor dental knowledge results in a very poor state of dentition.

- The low level of dental awareness among different socio-economic groups of pregnant women is probably due to the lack of educational programs targeted at pregnant women and new mothers in the Polish health care system.

- Like in the developed European countries, appropriate preventive strategies should be implemented as soon as possible.

\section{REFERENCES}

1. Cieśla B, Hanke W, Grodzicka A, Gulczyńska E, Pawłowska B, Wasilewska-Wilk E. [Use of prenatal health care and risk of infants born small-for-gestational-age. Preliminary results of a case-control study in the Łódź voivodeship]. Przegl Epidemiol. 2004;58(3):537-46. Polish.

2. Offenbacher S, Katz V, Fertik G, Collins J, Boyd D, Mayor $\mathrm{G}$, et al. Periodontal infection as a possible risk factor for preterm low birth weight. J Periodontol. 1996;67(10 Suppl):1103-13.

3. Boggess KA, Berggren EK, Koskenoja V, Urlaub D, Lorenz C. Severe preeclampsia and maternal self-report of oral health, hygiene and dental care. J Periodontol. 2013;84(2):143-51, http://dx.doi.org/10.1902/jop.2012.120079.

4. Wochna-Sobańska M. [Dental problems of pregnant women]. In: Pajszczyk-Kieszkiewicz T, editor. [Diseases co-existing with pregnancy]. Łódź: Medical University of Lodz Press; 2008. p. 575-92. Polish.

5. Li Y, Caufield PW. The fidelity of initial acquisition of mutans streptococci by infants from their mothers. J Dent Res. 1995;74(2):681-5, http://dx.doi.org/10.1177/0022034595 0740020901.

6. Alwaeli HA, Al-Jundi SH. Periodontal disease awareness among pregnant women and its relationship with socio-demographic variables. Int J Dent Hyg. 2005;3(2):74-82, http:// dx.doi.org/10.1111/j.1601-5037.2005.00121.x.

7. Opydo-Szymaczek J, Borysewicz-Lewicka M. [Dental care of pregnant woman]. Czas Stomatol. 2005;58(3):188-93. Polish.
8. Thorild I, Lindau-Jonson B, Twetman S. Prevalence of salivary streptococcus mutans in mothers and in their preschool children. Int J Paediatr Dent. 2002;12(1):2-7.

9. Jodkowska E, Wierzbicka M, Szatko F, Małkiewicz E, Strużycka I, Ganowicz M, et al. [Nationwide monitoring of oral health status and its conditioning. Oral health of children, 6 and 12 years old and adults in 35-44 years of age]. Warszawa: Ministry of Health; 2010. Polish.

10. Wierzbicka M, Jodkowska E, Szatko F, Pierzynowska E, Ganowicz M, Zawadziński M. [Social, economical and cultural aspects of oral health and dental needs of pregnant women in Poland]. Warszawa: Ministry of Health; 2006. Polish.

11. World Health Organization. Oral health surveys: Basic methods. 4th edition. Geneva: WHO; 1997. p. 21-52.

12. Wierzbicka M, Strużycka I, Szatko F, Ganowicz M. [Oral health in Poland at the turn of XXth and XXIst century]. Stomatol Wspolcz. 2012;19(3):8-16. Polish.

13. Chłapowska J, Opydo-Szymaczek J. [Analysis of the effect of the prophylactic program on the dentition status and health protecting habits in pregnant women - Clinical examination and questionnaire]. Dent Med Probl. 2006;43(1):59-64. Polish.

14. Janas A, Siciarz A, Białkowska-Głowacka J, Grzesiak-Janas G. [Analysis of pregnant women's behavior in aspect of surgical procedures]. Por Stomatol. 2008;8(5):124-7. Polish.

15. Szyszkowska A, Chmielewska M. [Pro-health awareness in pregnant women]. Por Stomatol. 2010;9:316-9. Polish.

16. Bassey GO, Anyanechi CE, Ekabua KJ, Ekabua JE. Oral health among antenatal care attendees in Calabar, Nigeria. J Obstet Gynaecol. 2010;30(2):143-6, http://dx.doi. org/10.3109/01443610903470262.

17. Dimitrova MM. A study of pregnant women's knowledge of children's feeding practice as a risk factor for early childhood caries. Folia Med (Plovdiv). 2009;51(4):40-5.

18. Douglass JM, Tinanoff N, Tang JM, Altman DS. Dental caries patterns and oral health behaviours in Arizona infants and toddlers. Community Dent Oral Epidemiol. 
2001;29(1):14-22, http://dx.doi.org/10.1034/j.1600-0528.2001. 00004.x.

19. Cruz GD, Roldós I, Puerta DI, Salazar CR. Community-based, culturally appropriate oral health promotion program for immigrant pregnant women in New York City. N Y State Dent J. 2005;71(7):34-8.

20. Clifford H, Johnson NW, Brown C, Battistutta D. When can oral health education begin? Relative effectiveness of three oral health education strategies starting pre-partum. Community Dent Health. 2012;29(2):162-7.

21. Thomas NJ, Middleton PF, Crowther CA. Oral and dental health care practices in pregnant women in Australia: A postnatal survey. BMC Pregnancy Childbirth. 2008;8:13, http://dx.doi.org/10.1186/1471-2393-8-13.

22. Ramos-Gomez F, Jue B, Bonta CY. Implementing an infant oral care program. J Calif Dent Assoc. 2002;30(10):752-61.

This work is available in Open Access model and licensed under a Creative Commons Attribution-NonCommercial 3.0 Poland License - http://creativecommons.org/ licenses/by-nc/3.0/pl/deed.en. 